\title{
A "ERA GRANBERY": APONTAMENTOS SOBRE A INSERÇÃO E CONSOLIDAÇÃO DO PROJETO EDUCACIONAL METODISTA EM JUIZ DE FORA (1890-1930)
}

Everton Fernando Pimenta ${ }^{1}$

\begin{abstract}
Resumo: Considerando o metodismo como a última etapa do Protestantismo Histórico, após discorrer brevemente sobre sua gênese e chegada à América, este artigo tem como objetivo precípuo analisar aspectos da atividade missionária realizada no Brasil por intermédio da Igreja Metodista Episcopal do Sul dos Estados Unidos, que intentava disseminar os ideais religiosos da denominação, os quais se entrelaçavam perfeitamente com certos elementos presentes na cultura norte americana. Para tanto, recorrendo a categorias de Antonio Gramsci e da Nova História Cultural, entendendo que as ações metodistas se pautavam pelo binômio educação e fé, se analisará de que forma, por meio do Instituto Granbery, se deu a inserção e consolidação do projeto educacional metodista, ao ponto da instituição se configurar como o grande celeiro de seus intelectuais durante o período da "Era Granbery", contribuindo para que a cidade de Juiz de Fora viesse a ser considerada o "Vaticano do Metodismo brasileiro".
\end{abstract}

Palavras-chave: Metodismo, Juiz de Fora, Granbery, Representações, Aparelhos privados de hegemonia.

\section{THE "GRANBERY ERA": NOTES ON THE INVOLVEMENT AND CONSOLIDATION OF THE METHODIST EDUCATIONAL PROJECT IN JUIZ DE FORA (1890-1930)}

\begin{abstract}
Considering the Methodism as the last stage of Historical Protestantism, after briefly discussing its genesis and arrival in America, this article has as its main objective to analyze aspects of the missionary activity carried out in Brazil through the Southern Methodist Episcopal Church of the United States, which sought to disseminate the religious ideals of the denomination, intertwining perfectly with certain elements present in American culture. To do so, using categories of Antonio Gramsci and the New Cultural History, understanding that the actions of the Methodists were guided by the binomial education and faith, this article will analyze how the involvement and consolidation of the Methodist educational project happened through the Granbery Institute, to the point where the institution became the great granary of its intellectuals during the period of the "Granbery Era", contributing to the city of Juiz de Fora to become considered the "Vatican of Brazilian Methodism."
\end{abstract}

Key-words: Methodism, Juiz de Fora, Granbery, Representations, Private devices of hegemony.

\section{"ERA GRANBERY": APUNTES SOBRE LA INSERCIÓN Y CONSOLIDACIÓN DEL PROYECTO EDUCACIONAL METODISTA EN JUIZ DE FORA (1890-1930)}

Resumen: Considerando el metodismo como la última etapa del Protestantismo Histórico, después de hablar brevemente sobre su génesis y llegada a América, este artículo tiene como objetivo primordial analizar aspectos de la actividad misionera realizada en Brasil por

\footnotetext{
${ }^{1}$ Doutorando em História pela Pontifícia Universidade Católica do Rio Grande do Sul (PUCRS). Este trabalho é um desdobramento da pesquisa de doutorado. Conta com o apoio da Capes. Professor de História na rede municipal de educação da cidade de Lavras-MG. E-mail: evertonpimenta@yahoo.com.br
} 
intermedio de la Iglesia Metodista Episcopal del Sur de los Estados Unidos, que intentaba diseminar los ideales religiosos de la denominación, los cuales se entrelazaban perfectamente con ciertos elementos presentes en la cultura norteamericana. Para ello, recurriendo a categorías de Antonio Gramsci y de la Nueva Historia Cultural, entendiendo que las acciones metodistas se basaban en el binomio educación y fe, se analizará de qué forma, por medio del Instituto Granbery, se dio la inserción y consolidación del proyecto educativo metodista, al punto de la institución configurarse como el gran granero de sus intelectuales durante el período de la Era Granbery, contribuyendo para que la ciudad de Juiz de Fora se considerara el "Vaticano del Metodismo brasileño".

Palabras clave: Metodismo, Juiz de Fora, Granbery, Representaciones, Aparatos privados de hegemonía.

\section{INTRODUÇÃO: O METODISMO E SUAS CARACTERÍSTICAS INICIAIS PRINCIPAIS}

O metodismo teve seu início na Inglaterra em 1739, por meio de John Wesley e de seus seguidores. Na esteira dos movimentos reformadores da Igreja Católica iniciados com Martinho Lutero em 1519, que deram origem às igrejas Luterana, Presbiteriana, Anglicana e Batista, tardiamente, a Igreja Metodista representou o encerramento de um longo processo histórico sendo, por isso, considerado como a última etapa do que se convencionou chamar de Protestantismo Histórico. ${ }^{2}$

Em meio a outros motivos, o Protestantismo Histórico visava a romper com a Igreja Católica por conta das acusações de degradação moral de parte de seu clero, mas, em especial, por causa de suas condutas reprováveis que exploravam a credulidade dos fiéis, tais quais a venda de indulgências e falsas relíquias. Além disto, divergia de práticas e princípios da Igreja Católica a exemplo do culto às imagens, da instituição do celibato, da realização de missas em latim e também por conta da autoridade papal ${ }^{3}$.

Diferenciando-se do anglicanismo - que, desde 1534, por iniciativa de Henrique VIII, se separou da Igreja Católica subordinada ao papa $^{4}$-, cuja atuação se dava mais sob a perspectiva litúrgica do que social, a um só tempo, intimamente vinculado à situação

\footnotetext{
2 Por Protestantismo Histórico entende-se o cristianismo praticado pelas Igrejas Presbiteriana, Luterana, Metodista, Anglicana e Congregacional que, apesar de se constituir como um movimento reformador, mantiveram elementos do cristianismo ortodoxo, a exemplo da crença na Trindade, da Bíblia como o único livro sagrado, entre outros.

3 À luz de diferentes perspectivas, sobre o protestantismo, ver: (CHAUNU, 1993; HILL, 1987 e MCGRATH, 2012).

${ }^{4}$ Isto decorreu das questões que envolviam o pedido de anulação de seu casamento com Catarina de Aragão para que contraísse matrimônio com Ana Bolena. Como o papa Clemente VII negou o pedido, a separação da Igreja Anglicana do primado de Roma se consumou em definitivo com o Ato de Supremacia que tornava a Igreja Anglicana subordinada ao rei (REGINA, 1960).
} 
vivenciada na Inglaterra nas décadas iniciais do século XVIII, sob a influência do arminianismo, do puritanismo, pietismo e individualismo, o metodismo atendia tanto aos anseios da burguesia e elite burocrática, quanto do proletariado inglês. ${ }^{5}$

Segundo Edward P. Thompson, foi durante os anos de guerra que se deu o grande crescimento do metodismo. Após, inicialmente, atrair um grande número de fiéis oriundos da classe operária, com a morte de John Wesley em 1791, ocorreram mudanças significativas como a proibição imposta à pregação por parte das mulheres, a renegação dos $\operatorname{ludistas}^{6}$ e o expurgo dos "metodistas primitivos", que realizavam reuniões ao ar livre e podiam, por isso, causar tumultos ou servir a propósitos políticos (THOMPSON, 1987, p. 226).

A explicação do alcance metodista ser maior entre o proletariado se devia ao fato de que, diferentemente do luteranismo, enquanto "religião do coração" e não do intelecto, para esta denominação, o alcance da graça era universal. Pobre ou rico, qualquer um que se arrependesse e confessasse seus pecados poderia receber a graça e, pelo sangue de Cristo, se redimir (THOMPSON, 1987, p. 241).

Nesta toada, apenas a palavra expressa na Bíblia Sagrada configurava-se como a autoridade a ser seguida, servindo de ligação entre Deus e os homens. Destarte, ao invés de manter o latim como a língua litúrgica, a exemplo do catolicismo que, assim, mantinha o clero numa condição de ponte para a salvação dos fiéis, o metodismo teve como uma de suas principais marcas a tradução e a distribuição de Bíblias em diversos idiomas com o fito de proporcionar a cada pessoa o meio para se obter a salvação.

Diferentemente do anglicanismo, instituição cristã oficial da Inglaterra, que dava pouca atenção para as massas oprimidas, o metodismo propunha uma ação voltada para a salvação do próximo tendo como objetivo a reforma da Igreja e da nação.

Nesse sentido, preconizava transmitir uma nova visão de mundo e fomentar o surgimento de um novo senso comum, de uma "nova cultura”, mirando, em última instância,

\footnotetext{
${ }^{5}$ Para uma explicação mais detalhada das características supracitadas do metodismo, ver: (CORDEIRO, 2003; MESQUIDA, 1994 e PIRES, 2013).

${ }^{6}$ Ludismo é a designação daquilo que pode ser considerado os primórdios do movimento operário inglês. Embora não se saiba ao certo a origem deste nome, acredita-se que ele derive do nome de seu líder ou iniciador Ned ou King Ludd. Ocorrido entre os anos de 1811 e 1816, o movimento ludista reuniu grupos de trabalhadores ingleses que se colocavam contrários às alterações que o desenvolvimento tecnológico decorrente da Revolução Industrial trouxeram para a vida do operariado inglês. De um modo geral, por meio das invasão das fábricas e destruição das máquinas, eles protestavam contra as péssimas condições de trabalho e os baixos salários, tomados como consequências do incremento da substituição da mão-de-obra humana pelas máquinas. Sobre o tema, entre outros, ver: (HOBSBAWN, 2004, p. 64-65 e THOMPSON, 1998, p. 281)
} 
uma melhora da formação intelectual e moral que seria levada a cabo por meio de sua atuação sustentada pelo binômio educação e fé (MESQUIDA, 1994).

Como a doutrina metodista da perfeição cristã, que apregoava a reforma da igreja e da nação por meio do ensino, não se compatibilizava com o analfabetismo, tornava-se necessário que seus fiéis soubessem ler para poder interiorizar os ensinamentos de seu fundador e da Bíblia. Por conseguinte, desde o princípio, se empenhou na construção de escolas argumentando que a aprendizagem seria o resultado de um processo de educação permanente e contínuo (MESQUIDA, 1994, p. 97-98).

Deste modo, como uma religião transnacional, ao ser transplantada para os Estados Unidos e, de lá, para o restante do continente americano, ainda que tenham se notado alterações importantes nos pressupostos que norteavam como deveriam se dar suas atividades missionárias, em sintonia com suas proposições iniciais, um de seus principais traços constitutivos seria o fato de que sua ação voltada para a conquista de fiéis se daria, mormente, pela inter-relação entre educação e fé.

\section{O TRANSPLANTE DO METODISMO PARA OS ESTADOS UNIDOS E AS NOVAS MARCAS IMPRESSAS ÀS SUAS CONCEPÇÕES}

Trazido para os Estados Unidos por missionários que haviam sido convertidos pelo próprio Wesley, o metodismo assumiu uma estrutura e linha de ação diferentes, influenciadas por aspectos inerentes à cultura e à política do país.

Sobre seus aspectos organizacionais, se, na Inglaterra, não constituiu uma igreja, ficando na dependência do clero anglicano, nos Estados Unidos, além de se conformar enquanto tal, teve uma disposição diferente, já que, sob a estrutura episcopal, possuía ministros itinerantes e laicos, realizando também pregações ao ar livre. Em relação às características advindas da cultura norte americana, elas decorrem da influência que elementos constitutivos desta, a exemplo do "mito da fronteira" e da ideia de "destino manifesto', exerceram sobre o metodismo, amalgamando-se em suas ações no interior do país e em sua expansão para o restante do continente (PIRES, 2013, p. 31-33).

Assim, influenciada pelos acontecimentos da história norte americana, sua ação missionária, ao se realizar na região da "fronteira", em decorrência de algumas características

\footnotetext{
${ }^{7}$ Pautada pelas colocações de H. Richard Niebuhr, a explicação dada por Ana Lúcia Meyer Cordeiro situa a "fronteira" como uma linha imaginária existente entre a "civilização" e as terras ermas, despovoadas, que se moveu até chegar ao Pacífico, no contexto da expansão para o oeste com o extermínio de populações indígenas (CORDEIRO, 2008, p. 31).
} 
do metodismo como, por exemplo, a prática religiosa informal - que não exigia a presença de pastores ou mesmo um templo para a realização dos cultos - e do fato de que muitos de seus pregadores que realizavam a atividade de colportagem e venda de Bíblias eram itinerantes, solteiros e dotados de um baixo preparo intelectual, com uma linguagem simples e acessível aos moradores de tal região inóspita, proporcionaram uma melhor adaptação aos ambientes inóspitos desbravados, permitindo que ele se tornasse a maior denominação protestante dos Estados Unidos. ${ }^{8}$

O resultado desta acomodação do metodismo à fronteira foi sua quase completa vitória sobre as igrejas coloniais mais antigas. A conferência metodista do Oeste aumentou o número de membros de 2.800 para mais de 11.000 no período de 1800 a 1805; em 1811, registrava mais de 30.000 membros. Do Kentucky e Tennessee os missionários cavalgavam para o Sul, Norte e Oeste. Ohio, Indiana e Illinois foram visitadas logo no começo de sua colonização pelos infatigáveis pregadores itinerantes, e o Missouri recebeu seu primeiro missionário metodista já em 1805. O metodismo andava passo a passo com o avanço da fronteira (NEIBUHR, apud, CORDEIRO, 2008, p. 32).

Dados seus pressupostos teológicos que apregoavam ser a condenação universal e que, para escapar a ela, o fiel deveria pautar suas ações cotidianas por valores morais e boas obras, entende-se que, estes, ao se amalgamarem à cultura que se forjava no país, ajudaram a propagar elementos que até hoje constituem valores partilhados pelo cidadão americano médio, a exemplo do voluntarismo, da crença no individualismo e na "excepcionalidade dos Estados Unidos" - por conta de seu desenvolvimento econômico -, elementos erigidos sobre a liberdade individual, um dos pilares de sua nação.

Portanto, a fusão do cristianismo metodista, que exigia sacrifícios e se colocava como "puro" e "superior", com elementos presentes na cultura norte americana como uma espécie de religião civil, que tomava seu povo como o escolhido a levar a salvação ao resto do mundo, acabou legitimando e fortalecendo sua "ação civilizadora" em relação aos povos da fronteira e de regiões mais distantes, como o Brasil.

\footnotetext{
${ }^{8}$ Ao se voltar para as ações dos metodistas na conquista do oeste, Jackson Luiz de Oliveira Pires lançou mão da noção de "zonas de contato". Essas seriam localidades nas quais culturas diferentes se fundiriam desarmonicamente, com a persistência de uma relação de dominação e subordinação, o que ajudaria a explicar o processo de transculturação, que seria o produto destas "zonas de contato", surgido das sucessivas interações destas culturas, nem sempre ocorridas de modo pacífico (PIRES, 2013, p. 24-25).
} 
A convicção de que os sinais do Reino de Deus são a liberdade (civil e religiosa), a civilização e o progresso, levava os metodistas a identificarem a nação americana como o povo escolhido por Deus para salvar o mundo. (...) Para os metodistas, as nações mais evoluídas tinham o dever de "civilizar" os povos atrasados do mundo, seja pela conversão dos pagãos, seja pela "recuperação" dos católicos ao "verdadeiro cristianismo", isto é, ao cristianismo protestante. Cristianizar as nações queria dizer "civilizá-las" de acordo com o modelo ideal: os Estados Unidos da América. (...) O nacionalismo metodista (ou seria uma religiosidade nacionalista?), que via os Estados Unidos como o "centro" de civilização e que propunha comunicar ao mundo os valores e os ideais da América do Norte, legitimando o expansionismo, contribuiu para a ação imperialista norte americana, tendo o liberalismo como referencial teórico e a teologia arminiano-metodista como elemento legitimador (MESQUIDA, 1994, p. 105-106).

Para levar a cabo estes intentos, a estratégia utilizada, há muito consolidada nos Estados Unidos, seria a atuação missionária associada às ações voltadas para as atividades educacionais ${ }^{9}$, posto que, por meio destas últimas, se poderiam propagar os ideais defendidos pelo metodismo, os quais, como se tentou demonstrar, se encontravam intimamente ligados a valores fundacionais da cultura americana.

\section{O METODISMO NO BRASIL E A OPÇÃO POR JUIZ DE FORA.}

Sem desconsiderar a primeira incursão metodista ocorrida no Brasil entre os anos finais da década de 1830 e iniciais da seguinte, interrompida por conta de infortúnios ocorridos com parte dos missionários aqui radicados, teria sido somente após o término da Guerra Civil Americana que a designação religiosa voltaria seus esforços para o país, pautando-se pelo binômio educação e fé (SALVADOR, 1982).

Sob tal perspectiva, juntamente das ações de proselitismo religioso, eram abertas escolas dominicais e paroquiais onde se ofertava um ensino básico aos fiéis para que pudessem interiorizar os ensinamentos da Bíblia e de John Wesley, além de escolas regulares que fomentariam o surgimento de lideranças e novos quadros do metodismo. ${ }^{10}$

A princípio, as ações metodistas centraram-se mais nas regiões sul e sudeste do Brasil. Embora existam diferenças em relação às atividades da denominação nestas, posto que, no Rio Grande do Sul, os primeiros missionários eram oriundos da região norte dos

\footnotetext{
${ }^{9}$ Para se ter uma ideia do sucesso do empreendimento educacional no país que, além de contribuir para a atração de novos fiéis, também ajudava a fomentar a criação de lideranças metodistas e laicas, entre 1831 e 1870, foram construídas mais de duzentas escolas e trinta e quatro universidades, o que colocou o metodismo como a mais poderosa agência educacional protestante norte americana.

${ }^{10}$ Sobre os objetivos destas modalidades de escolas metodistas, entre outros, ver: (BOAVENTURA, 1994; BOAVENTURA, MALUSÁ, 1996 e MATTOS, 2000).
} 
Estados Unidos e os que para a região sudeste rumaram vinham do sul, ainda que esta questão mereça um estudo a parte, por fugir aos intentos deste trabalho serão abordados apenas elementos mais gerais da ação educacional, em especial para as desenvolvidas em Juiz de Fora-MG.

Desta forma, superadas as supracitadas dificuldades enfrentadas decorrentes da Guerra Civil Americana, o metodismo retomou suas ações missionárias voltadas para o sudeste brasileiro, onde se localizavam cerca de três mil norte-americanos, fugidos da situação bélica vivida em seu país (BANDEIRA, 2007; PIRES, 2013).

A escolha por esta região, inicialmente pelo interior de São Paulo e, posteriormente, pela zona da mata mineira, se deu por conta de seu dinamismo econômico, atrelado à boa recepção aos valores e ideias norte-americanos veiculados pela denominação, por parte de suas elites, que se encaixavam aos princípios republicanos que defendiam (MESQUIDA, 1994, p. 48).

Além disto, a exemplo das lideranças metodistas, parte destas elites integrava a maçonaria, fato que fez com que a resistência à chegada dos missionários fosse menor, assim como o incentivo à abertura de escolas ocorresse pois, como grupos dirigentes dotados de um maior dinamismo, tais elites aspiravam que seus filhos fossem educados dentro de valores e ideias mais modernos do que aqueles ofertados nas escolas católicas.

Todos falavam a mesma "linguagem" e possuíam, portanto, os mesmos símbolos de expressão. Sua vinculação à organização maçônica estimulava ideais comuns. Ao lado do ideal republicano fomentado pelas lojas maçônicas e difundido pela imprensa posta à serviço da Fraternidade, havia também o fato de que a educação ocupava um lugar importante no movimento maçônico. Um novo contexto exigia uma maneira diferente de formar as novas gerações, seja a nível de conteúdo, seja com relação aos métodos didático-pedagógicos. As escolas protestantes nos Estados Unidos contribuíram eficazmente para a formação das elites liberais do país. Os intelectuais brasileiros vinculados aos fazendeiros do Oeste de São Paulo e da Zona da Mata, em Minas, estavam convencidos de que a educação norteamericana transferida para o Brasil poderia ser um instrumento de fundamental importância para inculcar no espírito dos filhos dos fazendeiros da Região Sudeste a confiança em si e o apego à liberdade individual e de empresa que, na sua opinião, haviam promovido a força da Grande Nação Americana" (MESQUIDA, 1994, p. 48).

À luz da intersecção de valores e demandas de parte das elites do sudeste que se encaixavam ao que era difundido pelos metodistas é que se entendem os porquês das 
atividades destes últimos terem se direcionado para a região, da qual se abordará, em especial, a zona da mata mineira nos próximos itens.

No entanto, antes de prosseguir, destaca-se que, além da atração de novos fiéis pelas instituições de ensino metodistas terem por objetivo a disseminação do ideário missionário norte americano - que congregava aspectos da religião protestante com o da cultura norte americana - e, por entender que suas ações cotidianas buscavam, nos termos gramscianos, implementar uma nova concepção de mundo, é preciso pontuar que elas serão aqui tomadas como intelectuais coletivos ou aparelhos privados de hegemonia que se encontravam estreitamente vinculados a aspectos socioeconômicos e culturais defendidos por seus apoiadores no país no período abordado.

Assim, as diversas associações (igrejas, meios de comunicação, partidos, sistema escolar, instituições de caráter científico e artístico, etc.) que formam a espinha dorsal da sociedade civil, chamadas por Gramsci de aparelhos privados de hegemonia, não são homogêneas e, na maioria das vezes, se apresentam como totalmente desvinculados da vida econômica e política da sociedade, pois atuam principalmente no campo da cultura. Este descolamento, porém, é apenas ilusório, afirma Gramsci, pois todas as formas de organização se remetem ao terreno da produção econômica e ao Estado, sendo que a concepção de Gramsci da sociedade civil é inseparável da noção de totalidade, isto é, da luta entre as classes sociais (NÉSPOLI, 2012, p. 7).

Como, para Gramsci, a relação entre o universo teórico e a práxis social não ocorre de maneira estanque, automática, mas sim obedece a uma lógica processual, o intelectual orgânico é entendido segundo a lógica de atuação que desenvolve pela ação do indivíduo ou do intelectual coletivo - aparelhos privados de hegemonia - que, por meio de suas atividades, atuaria para construir novas concepções de mundo que ajudariam a embasar uma nova hegemonia. ${ }^{11}$

Esta, substituiria a hegemonia então vigente, que exerceria um domínio sobre a forma de pensar, de agir e sobre as instituições em geral, por meio de certa ascensão que possui sobre as instâncias legislativas, executivas e judiciárias ou ainda por intermédio dos aparelhos privados de hegemonia que agem de modo a capilarizar na sociedade os valores e os ideários caros aos seus interesses, como seria o caso dos colégios criados pelos missionários metodistas norte-americanos.

\footnotetext{
${ }^{11}$ Sobre o conceito de hegemonia em Gramsci ver: (GRUPPI, 1978). 


\section{O GRANBERY EM SUAS DÉCADAS INICIAIS: UMA INSTITUIÇÃO MODERNA E DE ELITE}

Assim como no interior de São Paulo, a opção metodista por se instalar em Juiz de Fora se deu por conta de seu dinamismo econômico, proximidade ao Rio de Janeiro, mas também pela existência de uma elite defensora dos ideais liberais apregoados pela denominação religiosa, republicana e maçônica, que também ansiava por um modelo educacional mais próximo destes valores para a educação de seus filhos. ${ }^{12}$

Embora parte desta elite estivesse vinculada à antiga tradição senhorial, aristocrática, católica e conservadora, existiam pessoas com características modernas e seculares, influenciadas pelos ideais liberais, republicanos, maçônicos e positivistas que viam os Estados Unidos como modelo cultural, político e econômico para a modernização e progresso do Brasil e o protestantismo como a vanguarda da liberdade e da modernidade (CORDEIRO, 2003, p. 76).

As atividades de colportagem e os cultos na cidade e região começaram a serem realizados a partir do ano de 1884. Apesar de manifestações dos católicos contrárias a suas atividades, pouco tempo depois destes momentos iniciais, evidenciando que os trabalhos já apresentavam seus primeiros resultados, salta aos olhos que, em 1890, os metodistas já possuíam um templo - o primeiro de Minas e o terceiro do país - um periódico e uma escola (SALVADOR, 1982, p. 148; KENNEDY, 1928, p. 37; CORDEIRO, 2003, p. 83-85).

A última, inaugurada como Juiz de Fora High School and Seminary, em homenagem ao bispo da Igreja Metodista episcopal do Sul dos Estados Unidos que visitara o Brasil, J. C. Granbery, passou a ser denominada Collegio Americano Granbery, iniciando a "Era Granbery", na qual se transformou no maior centro educacional metodista da Primeira República (BOAVENTURA, 1994, p. 98).

Para se ter uma ideia do crescimento pelo qual ela passou no período, quando se observa o gráfico abaixo, percebe-se que, de fato, ele foi significativo, sendo necessário tentar entender quais fatores teriam contribuído para seu fortalecimento.

\footnotetext{
12 Dentre os aspectos que contribuíram para a inserção do metodismo na cidade, enfatizam-se três pontos: 1) Dada a distância dos centros do barroco mineiro, na cidade teria desenvolvido uma religiosididade católica diferente (NOVAES NETTO, 1997, p. 39-40); 2) Juiz de Fora era dotada de uma forte presença maçônica, cuja primeira loja já existia desde 1870 (CASTRO, 2008, p. 31-32); 3) A cidade também contava com lideranças políticas e intelectuais, a exemplo do Dr. José Caetano de Moraes e Castro - também maçom - que, se não foram signatários do Manifesto Republicano de 1870, ao menos integraram o movimento desde seus momentos iniciais (FERREIRA, 2010, p. 92).
} 
Gráfico 1: Número de matrículas da escola entre 1889 e 1929.

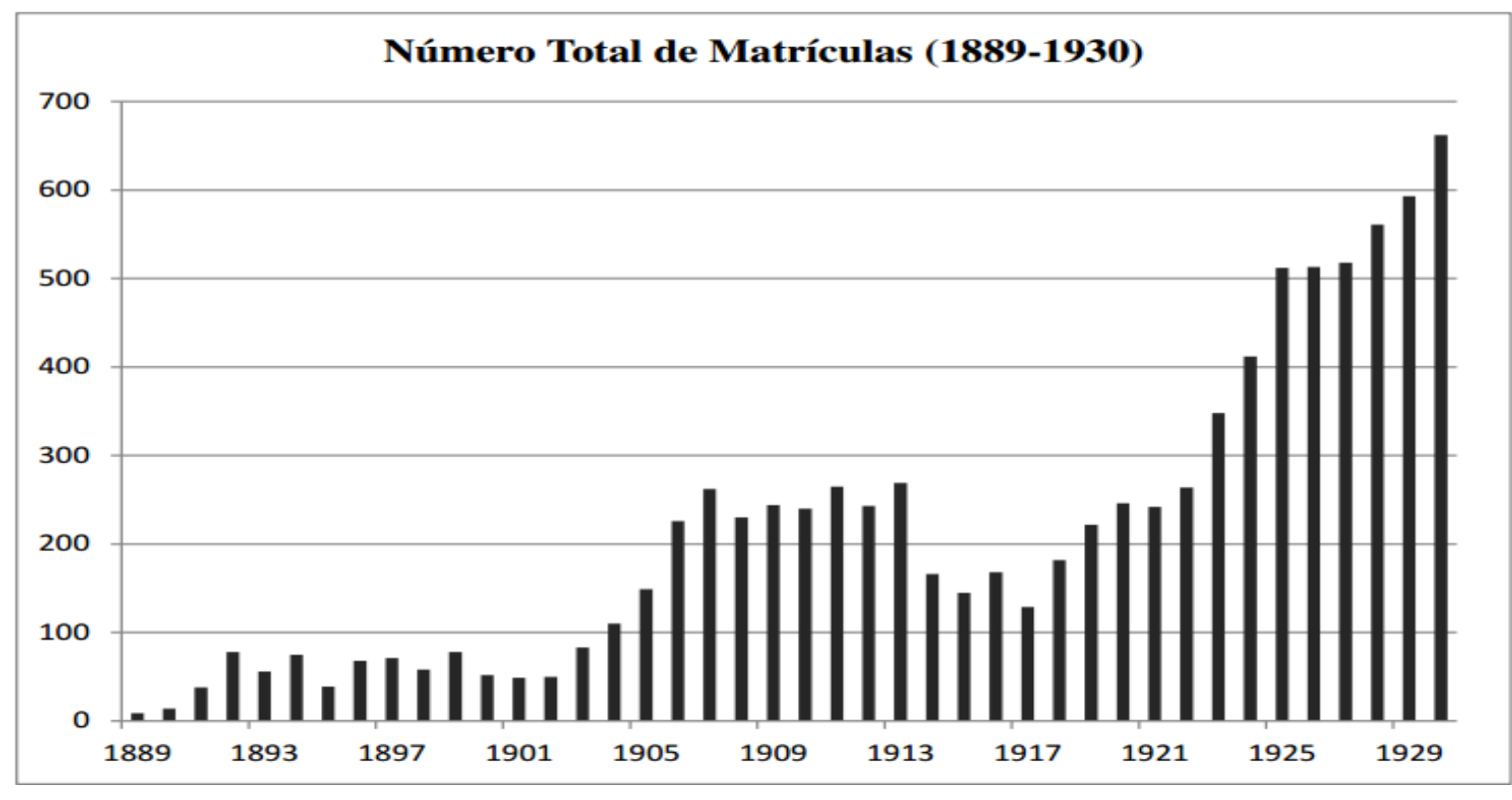

Fonte: (PIRES, 2013, p. 150)

Além dos motivos mencionados anteriormente, se conjectura que até, aproximadamente, meados da década de 1900, a expansão do número de matrículas poderia decorrer do fato de que somente após a inauguração do Granbery e da atração que ele exerceu sobre parte da elite local foi que a Igreja Católica teria se voltado para o setor educacional apresentando uma concorrência ao mesmo (MESQUIDA, 1994, p. 231).

Para todo o período contemplado pelo gráfico, junto aos fatores apresentados, entende-se que, ofertando um modelo de ensino voltado mais para aspectos práticos, com a utilização de laboratórios para a efetivação de um ensino utilitário pautado pela experimentação e verificação, realizada por meio de uma didática menos teórica e com uma valorização da prática esportiva que levaria ao constante progresso do aluno, o Granbery almejava se colocar como um centro de excelência cujos objetivos eram os de formar líderes que atuariam na sociedade contribuindo para seu progresso, além de preparar novos quadros para atuar no metodismo (FERREIRA, 2010, p. 78).

Sobre o último aspecto pedagógico, notadamente uma ferramenta inovadora para a época, tem-se que, desde a implantação do Granbery e de outros colégios metodistas, o 
esporte se notabilizou como uma parte integrante de seus currículos escolares, aspecto que se comprova quando se observam os diversos periódicos que eles produziram. ${ }^{13}$

Em decorrência da busca por atividades diferenciadas, um exemplo de modalidade que se fazia bastante presente nos educandários metodistas no Brasil, e que, aos poucos, se constituiu como uma marca de nossa cultura nacional, se remete à prática do futebol, cujo modo precoce como foi implantado no Granbery merece destaque, sobretudo, quando se compara a data da realização de sua primeira partida com a narrativa oficial comumente veiculada pela imprensa sobre sua gênese no país.

Isso se dá pois, se a primeira partida realizada por iniciativa de Charles William Miller, reunindo os funcionários da São Paulo Gás Company e da São Paulo Railway, teria ocorrido em 1895, sua prática no Granbery teria começado, ao menos, um ano antes (MOURÃO, 2014, p. 32).

Por iniciativa do reitor do Granbery, John McPhearson Lander, que conheceu o novo esporte em viagem à Inglaterra realizada em 1893, foi que o futebol foi introduzido na escola. Para tanto, em seu retorno ao Brasil, além de uma bola, ele trouxe também um livro de regras, conforme consta em um bilhete que sua filha, Margareth Lander, noventa e um anos depois, escreveu em visita à Juiz de Fora: "Nota referente ao primeiro jogo de futebol em 1894 papai o introduziu após assistir o jogo de futebol na Inglaterra em 1893. Ele trouxe a bola e um livro de regras e introduziu o jogo no Brasil”. Nota 8/11/84 (LANDER, 1984) ${ }^{14}$

Não obstante a pequena imprecisão quanto à data da primeira partida realizada no Granbery - Margareth Lander afirmou que ela teria ocorrido em 1894, ao passo que, no livro de cronologia do Granbery, do período de 1890 a 1897, a data correta seria a de 10/03/1893 tem-se que, juntamente do jogo de tênis, ele, de fato, foi, precocemente, introduzido na escola (Livro de cronologia do Granbery 1890-1897). ${ }^{15}$

Mais importante que o debate sobre a paternidade do futebol é destacar que no instituto, pautado pelo ideário liberal de progresso individual e de liberdade de escolha, ao se propor uma prática educacional ligada ao moderno modelo norte americano, o esporte tornou-

\footnotetext{
${ }^{13}$ Se o Granbery contava com um jornal desde seus primeiros anos, em Porto Alegre, fundado em 1923, Porto Alegre College, desde 1924 contava com o jornal O Reflexo e, após 1937, com o periódico Colunas nos quais o esporte recebeu uma ênfase considerável.

${ }^{14}$ No original: "Note reference to the first soccer game in 1894 - father introduced it after seeing soccer played in England in 1893. He brought a ball and a rulle book and introduced the game to Brazil. Note 8/11/84".

${ }^{15}$ John McPhearson Lander já havia confirmado esse pioneirismo ao, assim, descrever o evento: "Inaugurado football e tennis. O primeiro field day realizou-se em 24 de junho de 1893 , com saltos, corridas, indians clubs, tennis e football entre gregos e troianos" (LANDER, apud, NOVAES NETTO, 1997, p. 45). Para mais detalhes das partidas de futebol do Granbery ver: (PIRES, 2013, p. 137-139).
} 
se uma prática recorrente, configurando-se também numa das principais marcas da instituição. $^{16}$

Décadas depois, cristalizados como uma tradição das instituições de ensino metodistas, os esportes ainda ganhavam destaque como se pode observar na edição anual do periódico $O$ Granbery de 10/11/1928. Somando-se aos anúncios dos jogos realizados entre os alunos do Granbery, foi noticiada uma competição realizada no Rio de Janeiro, que reuniu também os alunos do Colégio Batista local e do Instituto Gammon, escola presbiteriana de Lavras-MG (O Granbery, 10/11/1928, p. 57).

Nesta ocasião, entre vitórias e derrotas dos alunos, sobreleva-se a relação que o Granbery mantinha com outras instituições de ensino de confessionalidade protestante, bem como o valor que era dado à competição esportiva como uma forma de, para além dos aspectos benéficos que traria para a saúde, se evidenciar o lado do mérito e a ideia do aperfeiçoamento pelo esforço do indivíduo.

Isto se coloca pois ficou patente que, mesmo com a inevitável rotatividade dos alunos na escola, objetivava-se manter a competitividade de suas equipes, fato que, conforme se observa no relato, teria sido alcançado ao final do ano.

Fomos ao Rio de Janeiro em abril. Não tinhamos ainda em forma os nossos teams, mas para concorrermos para o exito de uma festa do Collegio Baptista, fomos. Perdemos as partidas de volley e basket-ball, e vencemos a de foot. Logo depois veio o campeonato da Liga Baptista-Lavras-Granbery. Obtivemos o segundo logar. E si o campeonato não ficou em nossas mãos foi por falta de sorte. (...) Allias, não só os athletas; todos os nossos teams se achavam ainda em formação, pois se compunham de elementos quasi todos novos. (...) O rejuvenescimento dos nossos teams (...) tinha por força que nos trazer no princípio do anno serias dificuldades. Mas trabalhamos, e chegamos ao fim do anno com teams fortes e cohesos. Foi penna as circunstancias não permitirem os jogos de setembro com o Instituto Gammon (O Granbery, 10/11/1928, p. 57).

Por fim, em paralelo às práticas esportivas, Arsênio Firmino Novaes Netto destacou que havia na escola uma cultura de incentivo à participação política, inspirado no lema

\footnotetext{
${ }^{16}$ A modernidade destas modalidades praticadas no dia do field day, é significativa, pois, além de disputas de tênis, peteca, futebol, corridas de 200m e 500m e "Indian Clubs", - modalidade que não se conseguiu apurar do que se trata - também foi realizada no Granbery a prática de esportes não convencionais para a época, como, por exemplo, as competições de "Salto alto", "salto comprido", "salto comprido correndo", que se assemelham, respectivamente, às modalidades atuais de salto em altura, salto à distância e salto triplo. O fato de que estes esportes não eram muito convencionais, mesmo entre aqueles que se podem encontrar em competições de atletismo, sugere que suas práticas podem ter sido influenciadas pela retomada dos jogos olímpicos em 1896 quando o Barão de Pierre de Coubertin, após fundar o Comitê Olímpico Internacional, organizou os jogos em Atenas (Livro de cronologia do Granbery 1890-1897).
} 
"pensar e ser livre para pensar", que teria sido introjetado nos alunos por meio de dispositivos como os grêmios literários (NOVAES NETTO, 1997, p. 61).

Entrementes, na prática, o que se viu foi que, se a direção do instituto incentivava este exercício ambicionando dotar os alunos de certa proficiência para que eles viessem a atuar nessa esfera no futuro, isso de dava dentro de certos limites, atendendo a uma perspectiva utilitarista, sob a qual se intentava aumentar a influência metodista nos centros decisórios, cerceando os comportamentos que poderiam ser apreendidos como possíveis entraves para que esta viesse a se concretizar.

No que diz respeito à formação para a vida política, o que pode ser comparado ao que hoje os educadores chamam de currículo oculto, o Granbery, conclui-se, se empenhou em formar alunos com uma perspectiva fortemente utilitarista. Além disso, havia uma disposição, que também se repetia nos Estados Unidos, em auxiliar as autoridades públicas. Sabemos que essa disponibilidade estava ligada à busca pela simpatia dessas autoridades e constituía uma forma privilegiada de influenciar a sociedade (PIRES, 2013, p. 171-172).

Sob tal prisma, após serem tais órgãos criados no Granbery, houve, em 1903, um episódio que, a um só tempo, atestava a eficácia deste incentivo a este tipo de participação política dos alunos, bem como os aventados limites definidos para esta.

Ao afirmar que a direção da instituição concordava com a participação estudantil no "governo da comunidade colegial", foi aberto um espaço para que os alunos ginasianos, descontentes de não gozarem das mesmas liberdades dos alunos dos cursos superiores, entrassem em greve, situação que ensejou uma dura reação por parte da administração do instituto que enxergava ser este dispositivo reivindicatório um cancro social a ser extirpado.

Resolveu-se apoiar as congregações em todos os seus esforços para destruirmos o espírito de greve entre os alunos e, ao mesmo tempo, pedirlhes que empreguem todos os esforços ao seu alcance para extirpar esse cancro social. A Diretoria considera a greve um motivo de expulsão. (...) Resolveu-se enviar ao Ministro da Justiça um ofício representando contra as greves e pedindo seu auxílio ou apoio para extirpar esse mal, fazendo ver que os grevistas alegam sempre que elas são toleradas nos estabelecimentos oficiais (NOVAES NETTO, 1997, p. 61).

A despeito do hiato entre o discurso de si e a prática efetiva da liberdade de expressão e da participação política no Granbery ter sido detectado, o incentivo a este tipo de manifestação, tido como um exercício que, no futuro, renderia um maior poder de atuação aos 
alunos na esfera política, parece ter sido bem sucedido já que, egressos do instituto, a exemplo de Odilon Braga, alcançaram postos importantes como o de deputado federal e Ministro da Agricultura (NOVAES NETTO, 1997, p. 61). ${ }^{17}$

Para concluir acerca das décadas iniciais do Granbery, se estas eram as vigas mestras da educação que ele ofertava, entende-se que o sucesso que alcançou no interior das elites, a ponto de ser considerada a maior instituição de ensino metodista do país até 1930, sendo que, como reflexo disto, Juiz de Fora ficou conhecida como o "Vaticano do Metodismo no Brasil", ainda assim não pode ser explicado apenas por sua moderna proposta educacional (GONÇALVES, 2007, p. 72).

Era preciso mais. Era preciso ter um diferencial que se encontrava em seu corpo docente e no apoio que a intelectualidade e parte dos grupos dirigentes política e economicamente passaram a lhe ofertar.

\section{O GRANBERY: A BUSCA DO RECONHECIMENTO SOCIAL DE UM CELEIRO DE INTELECTUAIS}

Numa cidade na qual, além dos luteranos, que haviam chegado por volta de $1858^{18}$, só se faziam presentes os católicos, mesmo que, em decorrência do trabalho desenvolvido desde as primeiras ações de seus missionários, se reconheça o crescimento da comunidade metodista, é preciso ressaltar que ela era pequena e que, por mais que seus membros possam ter enviado seus filhos para estudar no Granbery, isto não seria o suficiente para explicar seu grande crescimento, posto que os custos eram elevados e muitos destes não possuíam condições financeiras para tanto. ${ }^{19}$

Logo, para compreender o sucesso alcançado pela escola, sobretudo após 1905, é preciso verificar como ela conseguiu atingir e ser aceita por setores da sociedade mais bem situados economicamente da sociedade.

\footnotetext{
${ }^{17}$ Outro egresso do instituto que obteve sucesso na esfera política foi Guaracy Silveira, deputado constituinte em 1934 e 1946 (OLIVEIRA, 2008).

18 Ver: Comunidade Luterana em Juiz de Fora comemora 150 anos. Disponível em: < http://www.ultimato.com.br/conteudo/comunidade-luterana-em-juiz-de-fora-comemora-150-anos >. Acesso em: 05/06/2017.

${ }^{19} \mathrm{Um}$ caso ilustrativo dos altos custos de se manter um estudante no Granbery se verificou na reunião da Assembleia Episcopal de Juiz de Fora, em 1932, quando foi relatado o afastamento da família de José de Brito das celebrações metodistas. Após terem sido analisados os motivos que causaram tal fato, foi descoberto que, por não ter condições financeiras o suficiente, ele havia requerido uma bolsa de estudos no colégio Granbery para seu filho. Contudo, como esta não foi concedida, ao obter tal benefício em um colégio católico da cidade, a família acabou por se afastar das atividades metodistas com receio de ser mal vista pelos outros metodistas (Livro Ata da Assembleia Episcopal de Juiz de Fora 1930-1934, 05/05/1932, p. 6-6.1).
} 
Nessa direção, se o modelo americano e os valores liberais foram grandes atrativos para parcelas da elite que tinham nos Estados Unidos o ideal de civilização, propõe-se aqui que os educadores americanos eram apreendidos como os interlocutores por meio dos quais seria possível se acessar tais coisas.

Tal assertiva se apresenta pois, desde as publicidades iniciais da escola, conforme se observa na imagem abaixo, que citava seu primeiro reitor John McPhearson Lander, ao se ofertar um ensino moderno, pautado pelo sistema americano, - adjetivado como firme e igualitário, nas modalidades de internato e externato - ao lado das propostas pedagógicas, se enfatizava a experiência e a origem norte americana de seus educadores, que funcionavam como um chamariz (Livro de recortes com as primeiras propagandas do Instituto Granbery. p. 1).

Imagem 1: Recorte com propaganda do Instituto Granbery do início do século XX

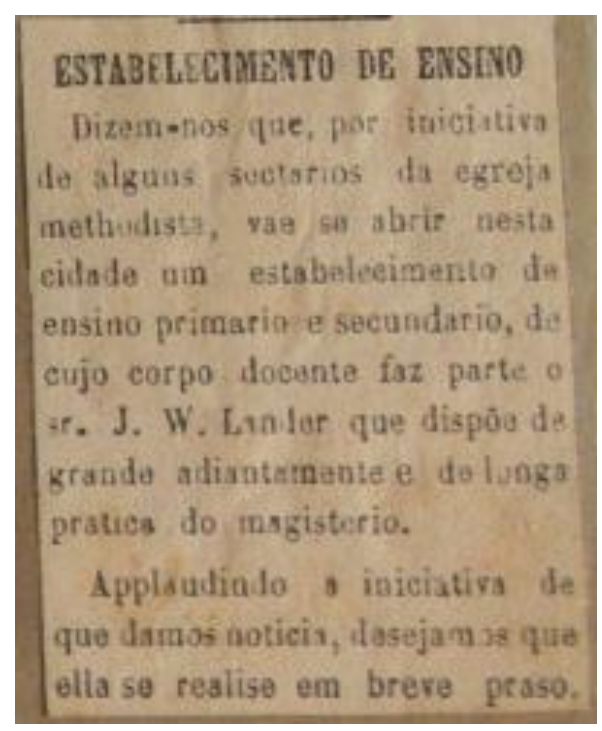

Fonte: Livro de recortes com as primeiras propagandas do Instituto Granbery. p. 1

Todavia, além do reitor, deve-se notar que os professores americanos eram poucos e, ainda que atuassem em sala de aula, costumavam acumular funções diretivas nas instituições de ensino, o que fazia com que a maior parte dos corpos docentes destas escolas fosse formada por brasileiros.

Mesmo que isto, a princípio, pudesse soar como paradoxal ao que se propôs até então, entende-se que, pela impossibilidade de compor o quadro de professores apenas com missionários ou ainda com profissionais contratados nos Estados Unidos, a opção pela 
contratação de intelectuais dotados de certa projeção local contribuiu decisivamente para que se minimizassem as reservas dirigidas à escola. ${ }^{20}$

A presença de membros destacados na elite intelectual local deu ao Granbery o respaldo e a confiança necessários para por em prática os seus projetos e foi de fundamental importância para a aceitação da introdução da educação metodista em Juiz de Fora e, no limite, para o desenvolvimento da própria instituição. A participação direta de muitos deles na instituição foi fundamental para limitar a ação oposicionista da Igreja Católica. De certo modo, esse apoio estava relacionado à modernização, representado pelo novo modelo de ensino "granberyense" e pelo americanismo representado pela presença dos missionários norte-americanos (PIRES, 2013, p. 105).

Foi, portanto, a fusão desse grupo de notáveis com os diferenciais oferecidos por seu modelo que fez com que o Granbery passasse a atrair alunos oriundos da nascente elite urbana juiz-forana, de cidades da região e de outros estados que, conforme afluíam com maior intensidade, ajudam a explicar o crescimento verificado no gráfico anteriormente apresentado, ao ponto de, em 1929, com mais de seiscentas matrículas, ele ter se consolidado como a mais importante instituição de ensino metodista do país.

Como reflexos da implantação de seu modelo educacional, por intermédio de seu renomado corpo docente, se percebe que, conforme o Granbery se colocava como uma instituição marcada de excelência, passava a atrair a simpatia de parte de políticos e da intelectualidade local, ao mesmo tempo em que, juntas, todas essas razões, aos poucos, contribuíam para a diminuição dos ataques que sofria de seus opositores.

O processo de construção desta representação positiva de si, que levaria ao consequente reconhecimento social por parte das elites políticas, econômicas e intelectuais, entre idas e vindas, foi sendo paulatinamente desenvolvido nas atividades cotidianas do Granbery e na recorrência à divulgação destas como, por exemplo, na publicação de suas propagandas em jornais locais.

À luz das proposições de Roger Chartier, se interpreta este expediente como uma tentativa de interferência nos embates de representações por parte dos diferentes grupos que

\footnotetext{
${ }^{20}$ Entre alguns nomes destes podem-se destacar os do Dr. Eduardo de Menezes, José Rangel, João Massena, Antônio Dias de Carvalho, José Dutra, Augusto Coelho de Souza e Moisés Andrade. Em 21/10/1926, na reunião da Congregação do Colégio Granbery, foi comemorado o fato do professor João Massena ter sido nomeado prefeito da cidade de Araxá-MG pelo presidente do estado de Minas Gerais, Antônio Carlos Ribeiro de Andrada (Ata da Congregação do Granbery, 21/10/1926, p. 58). Anos depois, em 31/03/1928, o jornal O Granbery informou que o Antônio Carlos Ribeiro de Andrada escolhera João Massena para dirigir a Escola Normal Modelo de Juiz de Fora, fato que o trouxe de volta para a Zona da Mata mineira e que encetou elogios ao exprofessor do Granbery (O Granbery, 31/03/1928, p. 3).
} 
comporiam a realidade social na qual o instituto se inseria, cujo intuito seria tornar a imagem projetada de si e de suas práticas hegemônicas para, assim, deslegitimar as representações divergentes sobre ele elaboradas por seus adversários.

\begin{abstract}
As representações não são de forma alguma discursos neutros: produzem estratégias e práticas (sociais, escolares, políticas) que tendem a impor uma autoridade à custa de outros, por elas menosprezados, a legitimar um projeto reformador ou a justificar, para os próprios indivíduos, as suas escolhas e condutas. Por isso essa investigação sobre as representações tem tanta importância como as lutas econômicas para compreender os mecanismos pelos quais um grupo impõe, ou tenta impor, a sua concepção do mundo social, os valores que são os seus, e o seu domínio. Ocupar-se dos conflitos de classificações ou de delimitações não é, portanto, afastar-se do social (...), muito pelo contrário, consiste em localizar os pontos de afrontamento tanto mais decisivos quanto menos imediatamente materiais (CHARTIER, 1990, p. 17).
\end{abstract}

Para tanto, além de realçar suas modernas concepções pedagógicas e a competência de seu corpo docente, a publicização da boa relação que possuía com a intelectualidade local simpatizante destas, que, inclusive, participava de eventos do instituto, conforme demonstrou a nota abaixo reproduzida - que atestou que o ex-vereador e adepto do movimento republicano Dr. José Caetano de Moraes Castro havia proferido um discurso por ocasião do encerramento do ano letivo em novembro de 1892 - transformou-se em uma estratégia fundamental para que a representação positiva que o colégio buscava impor de si se saísse vitoriosa nos embates contra seus inimigos. 
Imagem 2: Informe sobre as festividades de encerramento do ano letivo do Instituto Grambery de 1892

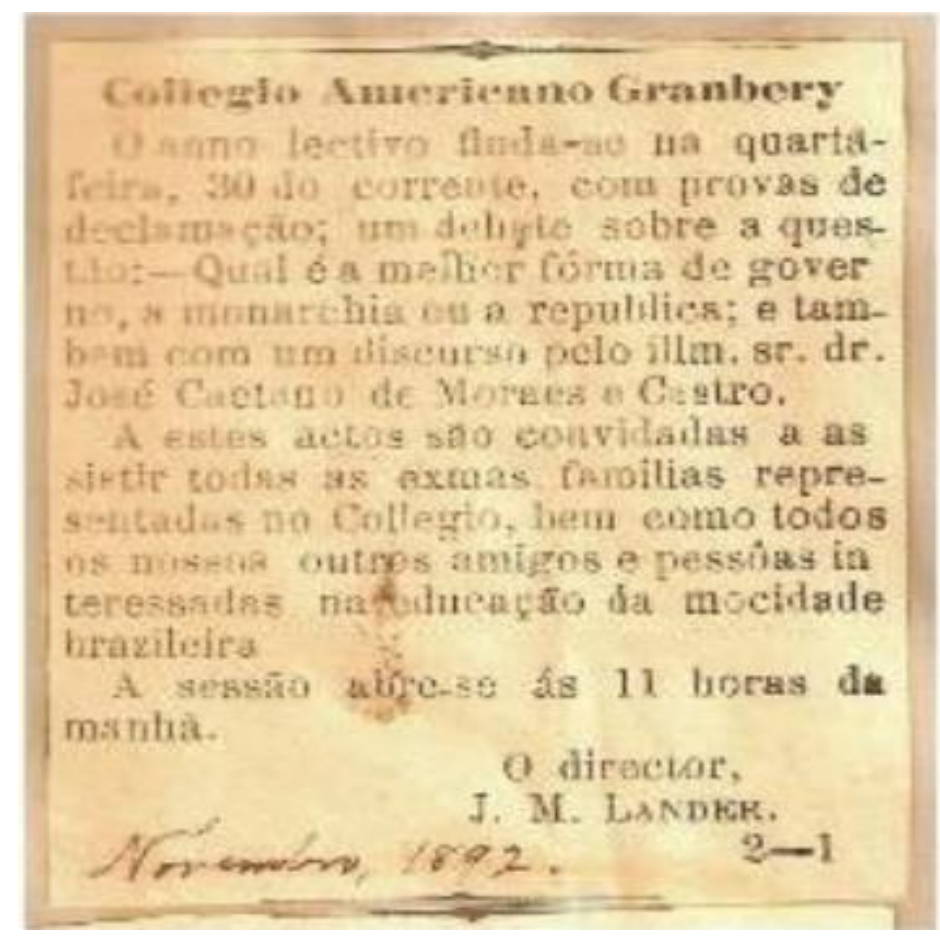

Fonte: Livro de recortes com as primeiras propagandas do Instituto Granbery. p. 4

\section{O SONHO DA UNIVERSIDADE METODISTA DO BRASIL}

Com a cada vez mais crescente consolidação de seu modelo educacional que, aos poucos, angariava mais alunos e reconhecimento, percebeu-se que, desde o início do século XX, o Granbery buscou ampliar sua atuação, apresentando planos ambiciosos.

Esses tiveram início quando sua administração requereu do governo federal sua equiparação ao Colégio Pedro II em 1903, o que lhe permitiria fazer os reconhecimentos de seus diplomas, seguidos da implantação de dois cursos superiores em 1904:

Depois de treze anos de trabalho honroso, a sua diretoria resolveu, em junho de 1903, modelar o seu curso de conformidade com os programas de ensino publico, e requerer do Governo Federal a sua equiparação ao Ginasio Nacional. Em 8 de Novembro de 1930, foi atendido esse requerimento, pela nomeação de um fiscal junto ao Granbery, e a instituição entrou em nova fase de existência. Na mesma ocasião foi resolvido pela Diretoria crear mais os cursos de Odontologia e Farmacia e, no dia 1 de Outubro de 1904, as aulas destes novos curso abriram-se ao publico. O curso teologico já existia anexo ao Colegio desde o principio; nesse mesmo ano de 1904, porém, com a nomeação de novos professores, esse curso foi remodelado e muito 
aumentado (Prospecto do O Granbery instituto de ensino americanobrasileiro, 1933, p. 9-10).

O pedido de equiparação do Granbery ao Ginásio Nacional foi aprovado em 1905, após a direção do Instituto ter recebido o apoio de diversos políticos e intelectuais locais que subscreveram uma moção de apoio que, além desta mudança, também solicitava que o Instituto viesse a ofertar cursos superiores, num ato que comprova o estreitamento de sua relação com boa parcela de suas elites locais e sua consolidação como o mais importante centro educacional da cidade e região.

Nós, abaixo assignados, sabedores da feliz lembrança, que teve a corporação americana do Collegio Granbery de equiparar este estabelecimento ao Gymnasio, e plenamente convencidos da grande vantagem, que traz consigo tão alevantado comettimento não só para Juiz de Fóra como para todo o Estado de Minas, vimos, por esta moção de solidariedade, protestar nosso incondicional apoio à Directoria do mesmo Collegio, que, convertido mais tarde numa Universidade, como é do intento dos illustres promotores de tão acertada idéa, de alto alcance, agora e no futuro, virá preencher uma lacuna, de que nos resentimos na actualidade. Juiz de Fóra, 16 de Junho de 1901 (MOÇÃO DE SOLIDARIEDADE, 16/06/1901).

Dentre as pessoas que assinaram o documento encontravam-se membros da intelectualidade local como médicos, advogados, farmacêuticos, funcionários públicos, engenheiros, tabeliões, juiz, escrivão, entre outros, sendo que alguns deles viriam a fazer do quadro de professores dos cursos de Farmácia e Odontologia, que foram inaugurados em 1904 dando prosseguimento aos intentos de expansão do Instituto (NOVAES NETTO, 1997). ${ }^{21}$

Contiguamente a esta proximidade com a intelectualidade, também se notou a existência de boas relações que o Instituto manteve com parcelas da classe política local, que se encontravam receptivas aos valores liberais que ele cultivava em seu modelo.

\footnotetext{
${ }^{21}$ São elas: os médicos Dr. Eduardo de Menezes, Dr. Leocadio Chaves, Dr. Belisario Pena, Dr. Azarias de Andrade, Dr. Cornelio Goulart Villela Bueno, Dr. Virgilio Falesano Alvez e Dr. Casimiro Villela de Andrade, os bacharéis Francisco Candido da Gama Junior, José Eloy de Araujo e Lafayette Barbosa Rodrigues Pereira, os advogados Tobias Toulendal, Gustavo Penna, Barão de S. Marcellino, Carlos Ferreira de Souza Fernandes, Francisco Pinto de Moura, Francisco Valladares, Affonso Augusto de Oliveira Penna e J. Luiz de Costa e Silva, os tabeliões João Chrysostemo Pimentel Barbosa e Arnaldo de Moraes e Castro, o juiz de direito avulso Josimo Alcantara Araujo, os engenheiros Julio Cezar Barboza Pena e Carlos Guedes de Castro, o jornalista Heitor Guimaraes, o agricultor Manuel Alves da Silva, o escrivão de órfãos Ignacio Ernesto Nogueira da Gama, o inspetor da Escola Municipal, José Luiz da Cunha Horta, os comerciantes M. Silva Lemos e Cornelio Gama, os funcionários públicos Manoel Ferreira Velloso, Mario da Cunha Horta e Martinho Pereira da Silva, os farmacêuticos, José Rangel e Sabino Monteiro Lemos, o dentista Agnello Firmino Quintella, além dos nomes cujas profissões não estavam especificadas, a exemplo de Antonio Bernades Fraga, Luiz de Oliveira, Adolpho Pereira, Antonio Rosa da Costa, J. Voyane, Alfredo Moreira Rezende, Arthur Siqueira e Francisco Augusto de Souza Lima (Moção de Solidariedade, 16/06/1901).
} 
No que diz respeito ao apoio externo, encontramos significativo suporte no Jornal do Comércio de Juiz de Fora, órgão do Partido Republicano ligado à Associação Comercial da cidade, fundado, em 1896, por Vicente de Leon Annibal, que o vendeu no ano seguinte para Antônio Carlos Ribeiro de Andrada (1870-1946), político nascido em Barbacena que chegou a ser deputado federal e um dos colaboradores da publicação. Em 1911, Francisco de Campos Valadares assumiu a propriedade do jornal; este já era o dono de outro importante jornal da cidade, "O Pharol" (PIRES, 2013, p. 105).

Como se tentou demonstrar, se a aproximação com tais grupos favoreceu a criação de uma imagem positiva da instituição na cidade, também possibilitou galvanizar apoio para projetos maiores como foi o caso da tentativa de se criar uma escola de medicina.

A esse respeito, contando com intelectuais como Dr. Eduardo de Menezes, José Massena, José Rangel e também políticos e empresários como Francisco Valadares, entre os meses de abril e maio de 1908, foi publicado o projeto da criação da escola de medicina na cidade que, seguido por outros inúmeros artigos sobre a mesma temática, demonstram como se dava no cotidiano a contínua construção e fortalecimento dessa imagem positiva amparada no apoio destes grupos intelectuais (PIRES, 2013, p. 155).

Associados, estes materiais, que tinham como intuito fomentar as discussões a respeito do projeto, confirmam que as estratégias utilizadas pelos metodistas surtiram efeito, pois, em diferentes momentos, eles conseguiram reunir o apoio de significativos próceres da intelectualidade e da classe política local regional e estadual ${ }^{22}$ e, especificamente sobre o Granbery, contribuíram para que ele criasse e consolidasse sua imagem de um centro moderno, progressista, que se associava aos Estados Unidos e ao ideal de desenvolvimento orientado pelo liberalismo econômico:

Há de fato uma troca de apoio entre o projeto educacional granberyense, considerado modernizador, e a elite intelectual de Juiz de Fora. O desenvolvimento da cidade e a concretização da aposta de que ali nasceria um centro progressista era desejado pelos missionários metodistas, contanto

\footnotetext{
${ }^{22}$ Entre eles estavam: “C. Malta, A. de Andrade, José Tristão de Carvalho, J. Mendonça, Eloy de Andrade, Bras Bernardino Loreiro Tavares, Albino Machado, Fernando de Moraes, Ambrósio Braga, José Marciano Loures, Hermenegíldo Villaça. J. L. do Couto e Silva, Candido Teixeira Tostes, Mello Brandão, J. Procópio Teixeira, Cornélio Goulart Bueno, Feliciano Penna, B. Aroeira, Luiz de Souza Brandão, Duarte de Abreu, Jayme Gonçalves, Martinho da Rocha, Christovam Pereira Nunes, V. Garcia, Luiz Barbosa Medeiros Gomes, F. Bernardino Rodrigues Silva, João Evangelista da Silva Gomes, Pinto de Moura, J. Navas, José Cesário Monteiro da Silva, João Penido, Barão de Cattas Altas, o editor e chefe do Jornal do Commercio, Francisco Valadares, o então presidente da câmara dos vereadores Antônio Carlos Ribeiro de Andrada e os professores do Granbery Eduardo de Menezes, Brant Horta. (...)As administrações de outras cidades também foram mobilizadas como, por exemplo, Lavras, Ponte Nova, Além Paraíba, Uberaba, Caxambu, Formiga e Belo Horizonte, que responderam positivamente. Considerando essas e outras manifestações, podemos perceber que a adesão ao projeto foi expressiva, mobilizando um grande número de homens públicos e de letras e a acolhida de diversas administrações" (PIRES, 2013, p. 156-158).
} 
que estes pudessem influenciar diretamente. Na mesma medida, para a realização das ambições da elite liberal juiz-forana, não se poderia prescindir de nenhuma das instituições locais de prestígio. Muito menos uma que representava o modelo de progresso em maior evidência, ou seja, o americanista (PIRES, 2013, p. 158-159).

Isto ficou evidente quando, em 1910, o poeta Olavo Bilac destacou o transplante do modelo norte americano de educação como algo importante e, em cerimônia de formatura dos alunos do Granbery, realizada no Teatro de Juiz de Fora, enalteceu os valores liberais propagados pela instituição:

Nenhuma outra missão poderia ser mais agradável ao meu espírito, que trago há bastante tempo preocupação com problemas do ensino. E meu contentamento é aumentado pela simpatia especial que me inspira o Ginásio Granbery, onde se aplicam com escrúpulos rigorosos as normas da educação moderna, segundo o critério adotado nos Estados Unidos da América, normas que podem resumir deste modo: no curso primário, a formação do espírito da criança, sem prejuízo de sua individualidade, no curso secundário, a formação do espírito do homem, dando-lhe equilibradamente a cultura das aptidões imaginativas e o conhecimento da vida prática, e inspirando-lhe sobretudo a confiança em si mesmo, base e ponto de partida de toda iniciativa individual (BILAC, Apud NOVAES NETTO, 1997, p. $28)^{23}$.

Embora nem o projeto da criação da escola de medicina, tampouco o da criação de uma Universidade Metodista ${ }^{24}$ tenham sido exitosos no período, pelo reconhecimento de seu modelo, de seu corpo docente e de suas articulações com parte da intelectualidade e classe política, ao longo da Primeira República, o Granbery se consolidou como a mais importante instituição de ensino metodista e atraiu gente do Brasil todo por conta da imagem que conseguiu criar de si e veicular de maneira hegemônica.

Para concluir, sobre seus intentos e atuação, é necessário enfatizar que, concomitantemente à intenção de implementar seu modelo educacional e atuar para forjar futuras lideranças, um dos objetivos principais do Granbery era também o de perparar novos quadros para a Igreja Metodista, público que se diferenciava bastante dos filhos das elites.

Os futuros pastores e professores que lá estudaram, a exemplo de Cesar Dacorso Filho, que viria a ser o primeiro bispo metodista brasileiro, entre tantos outros, majoritariamente, eram filhos de famílias que possuíam poucos recursos, fato que tornava

\footnotetext{
${ }^{23}$ Trecho do discurso de Olavo Bilac pronunciado na cerimônia de Colação de Grau do Ginásio d'O Granbery (Juiz de Fora, Typographia Brasil, 1910, p. 5).

${ }^{24}$ Ver: (NOVAES NETTO, 1997, p. 91-171).
} 
inviável o custeamento de seus estudos. Em decorrência disto, além de ofertar bolsas de estudo a esses alunos, eles trabalhavam na instituição como uma contrapartida do benefício que recebiam.

Sem embargo, aliado àquilo que dirigia aos filhos da elite, estes aspirantes ao magistério e ministério metodista também eram forjados enquanto futuros intelectuais que, organicamente ligados à denominação religiosa, iriam propagar o metodismo tornando-se os difusores de seu ideário com vistas a criar uma nova hegemonia que em muito diferia do estado de coisas que eles encontravam no país desde sua chegada.

Para Elias Boaventura, na década de 1920, a forma como o Granbery lidava com os futuros intelectuais metodistas exemplifica inequivocamente estes intentos que, a exemplo daquele voltado para as famílias da elite, também foram exitosos:

No Granbery, como de resto em todas as instituições metodistas, a questão do pobre enquanto categoria, na década de 1920, não esteve posta de modo sistemático, a exceção do pobre com tendência pastoral, que era escolhido e treinado para o ministério e magistério metodistas (BOAVENTURA, 1994, p. 97).

Ao fim e ao cabo, pelos motivos apresentados, no conjunto das instituições escolares fundadas pelo metodismo no Brasil, que tinham como intuito, além de atrair fiéis para a Igreja Metodista, disseminar na sociedade brasileira os ideais missionários, é que se entendem os motivos pelos quais se viveu a "Era Granbery” até 1930.

\section{CONCLUSÃO}

Em concordância com o estudo de Peri Mesquida, se poderia propor que, funcionando como um aparelho privado de hegemonia, cujo intuito era disseminar os valores da missão metodista resultantes da mescla entre as proposições da denominação e a cultura norte americana, o Granbery, concomitantemente, conseguia se voltar para as elites locais, congregando uma educação moderna com o proselitismo religioso e também se dedicar à formação de novos quadros do metodismo.

Pautando-se por aspectos da cultura norte americana como o mito da fronteira e a lógica do destino manifesto, atuava de modo a contribuir para que se criasse no Brasil uma nova hegemonia sob o alicerce do liberalismo político e econômico vigentes nos Estados Unidos, caminho pelo qual a denominação chegou à América do Sul. 
Ao conseguir se apresentar como um expoente deste modelo norte americano, que estava em consonância com o que se observava em boa parte dos países centrais do ocidente neste contexto da Primeira República, entende-se que o colégio cumpriu bem a sua função pois, além de terem surgido muitos intelectuais e políticos renomados que foram por ele formados, pode-se dizer que, muitas décadas depois desta conjuntura ora analisada, quando Itamar Franco, que foi um de seus tantos alunos, chegou à Presidência da República, o projeto de forjar lideranças atingiu seu ápice.

Pelo que se viu, em que pese a diferença entre discurso de incentivo à participação política e a prática desta, a exemplo do ocorrido com Itamar Franco, Guaracy Silveira e Odilon Duarte Braga, muitos destes ex-alunos conseguiram levar essa experiência para a vida posterior à sua estada no Granbery, vindo a ocupar importantes posições nesta esfera, situação que, ainda assim, pode-se propor que tenha sido, em parte, derivada da educação recebida no instituto.

\section{FONTES}

\section{a) Arquivo Ministério da Memória da Igreja Metodista Central de Juiz de Fora}

\section{Ata da Assembleia da Igreja Episcopal de Juiz de Fora 1930-1934}

Ata da Assembleia da Igreja Episcopal de Juiz de Fora 1930-1934, 05 mai. 1932, p. 5.1-8.

\section{b) Arquivo Histórico do Instituto Metodista Granbery.}

\section{Periódico: $O$ Granbery}

Athletismo e esportes. O Granbery, 10 nov. 1928, p. 57.

Dr. J. Massena. O Granbery, 31 mar. 1928, p. 3.

\section{Atas da Congregação do Granbery}

Ata da Congregação do Granbery, 21 out. 1926, p. 58.

\section{Prospectos e materiais diversos do Granbery}

Estatuto d' O Granbery, 1941.

Livro de cronologia do Granbery 1890-1897.

Livro de recortes com as primeiras propagandas do Instituto Granbery.

Moção de Solidariedade. Livro de recortes com as primeiras propagandas do Instituto Granbery, p. 19. 16 jun. 1901. 
Nota escrita por Margareth Lander sobre o início da prática do futebol no Granbery (1984).

Prospecto do O Granbery instituto de ensino americano-brasleiro, 1933.

\section{REFERÊNCIAS}

BANDEIRA, Luiz Alberto Moniz. Presença dos Estados Unidos no Brasil. Rio de Janeiro: Civilização Brasileira, 2007.

BOAVENTURA, Elias. Instituições Metodistas de Ensino na República Velha. Revista de Educação Cogeime, n. 5, 89-100, dez. 1994.

BOAVENTURA, Elias; MALUSÁ, Silvana. Escolas Paroquiais Metodistas. Revista de Educação do Cogeime, v. 5, n. 9, 83-98, 1996.

CASTRO, Giane de Sousa. A cruz e o compasso: o conflito entre igreja católica e maçonaria no contexto da questão religiosa e da reforma católica ultramontana. Dissertação de Mestrado. Juiz de Fora: UFJF, 2008.

CHARTIER, Roger. A História Cultural entre práticas e representações. Rio de Janeiro: Bertrand Brasil, 1990.

CHAUNU, Pierre. O Tempo das Reformas (1250-1550). II A Reforma Protestante. Lisboa: Edições 70, 1993.

CORDEIRO, Ana Lúcia Meyer. A inserção do metodismo em Juiz de Fora: uma história de conquista e tensões. Juiz de Fora: Letras e Notas, 2003

. Metodismo e educação no Brasil: as tensões com o catolicismo na primeira república.

Tese de doutoramento. Juiz de Fora: UFJF, 2008.

FERREIRA, Vanessa Barbosa Leite. GRANBERY: um colégio americano no Brasil. A prática do modelo americano de ensino em Juiz de Fora (1889-1930). Dissertação de mestrado. Juiz de Fora: UFJF, 2010.

GONÇALVES, Leandro Pereira. Tradição e cristianismo: o nascimento do Integralismo em Juiz de Fora. In: SILVA, Giselda Brito. Estudos do Integralismo no Brasil. Recife: Editora da Universidade Federal Rural de Pernambuco, 2007. p. 81-96.

GRUPPI, Luciano. O conceito de hegemonia em Gramsci. Rio de Janeiro: Graal, 1978.

HILL, Christopher. O mundo de ponta-cabeça: ideias radicais durante a Revolução Inglesa de 1640. São Paulo: Companhia das Letras, 1987.

HOBSBAWM, Eric. A era das revoluções. Rio de Janeiro: Paz e Terra, 2004. 
KENNEDY, James L. Cincoenta annos de metodismo no Brasil. São Paulo: Imprensa Metodista, 1928.

MATtOS, Paulo Ayres. Mais de um Século de Educação Metodista: Tentativa de um sumário histórico teológico de uma aventura educacional. Piracicaba: Cogeime, 2000.

MCGRATH, Alister. A Revolução Protestante - uma provocante história do protestantismo contada desde o século XVI até os dias de hoje. Brasília: Editora Palavra, 2012.

MESQUIDA, Peri. Hegemonia norte-americana e educação protestante no Brasil. Juiz de Fora: EDUFJF; São Bernardo do Campo: Editeo, 1994.

MOURÃO, Raul. No país da Copa, o futebol como ciência. Revista A3, v. 6, 32-39, Juiz de Fora, Abril a Agosto/2014. Disponível em: <http://www.ufjf.br/revistaa3/todas-as-edicoes2/revista-a306/>. Acesso em: 04/05/2017.

NÉSPOLI, José Henrique Singolano. Gramsci e a interpretação da sociedade civil na política contemporânea. In: Anais do VII Simpósio Nacional Estado e Poder: sociedade civil, 2012, Uberlândia. VI Simpósio Nacional Estado e Poder: Cultura, 2012. Disponível em: <http://www.historia.uff.br/estadoepoder/7snep/docs/049.pdf >. Acesso em: 10/05/2017.

NOVAES NETTO, Arsênio. As crises de um ideal: os primórdios do Instituto Granbery. Piracicaba: Editora Unimep, 1997.

OLIVEIRA, Cilas Ferraz de. Nunca, na história deste país... A contribuição de Guaracy Silveira ao metodismo do Brasil. Tese de doutoramento. Piracicaba: UNIMEP, 2008.

PIRES, Jackson Luiz de Oliveira. Empreendimento missionário americano: o modelo educacional granberyense e o universo político cultural de Juiz de Fora (1889-1930). Dissertação de mestrado. Niterói: UFF, 2013.

REGINA, Giuseppe. O Anglicanismo: Panorama Histórico e Síntese Doutrinária. São Paulo: Paulinas, 1960.

SALVADOR, José Gonçalves. História do Metodismo no Brasil. Rio de Janeiro: Centro Editorial Metodista de Vila Isabel, 1982.

THOMPSON, Edward Palmer. A formação da classe operária inglesa. Rio de Janeiro: Paz e Terra, 1987. v. 2.

. Costumes em comum. São Paulo: Companhia das letras, 1998.

Recebido em: 28/09/2017

Aprovado em: 05/01/2018 